\title{
The Effects of Previous Experience and Self Efficacy on the Acceptance of e-Learning Platforms Among Younger Students in Saudi Arabia
}

\author{
Omar Sulaymani \\ The International and Foreign Education Office in Makkah Region, Saudi Arabia \\ ORCID: 0000-0003-3882-9802 \\ Ahmad R. Pratama \\ Department of Informatics, Universitas Islam Indonesia, Yogyakarta, Indonesia \\ ORCID: 0000-0003-0372-5851
}

Moneer Alshaikh

Department of Cybersecurity, College of Computer Science and Engineering, The University of Jeddah, Jeddah, Saudi Arabia

ORCID: 0000-0002-2895-3482

\section{Ali Alammary}

College of Computing and Informatics, Saudi Electronic University, Jeddah, Makkah Region, Saudi Arabia ORCID: 0000-0002-4186-5786

Received: 19 Oct 2021

Accepted: 25 Nov 2021

\begin{abstract}
In Saudi Arabia, some e-learning initiatives such as the Future Gate Project (FGP) and Madrasati (MySchool) have been in place since 2018 and 2020, respectively. Amid the COVID-19 pandemic, they were used as a means of distance learning for students across the country. This paper investigates the willingness of students to use the e-learning platforms and whether it varies across different sex and age group. Primary data in the form of a survey of 265 secondary school students across the Makkah region was analysed with Structural Equation Modelling (SEM) by using the Technology Acceptance Model (TAM) as a theoretical framework. We found that students' self-efficacy, which is strongly influenced by their previous experience with the underlying technology used in the e-learning platforms, has a positive effect for older students in high school, yet surprisingly, a negative one for younger students in middle school. We also found that perceived ease of use and social influence to be the most important factors behind the students' acceptance of e-learning platforms and that the effects are stronger for female students than for male students. While this study was conducted in Saudi Arabia, the findings from this study provide a first-hand insight that can help ensure the continuity of the e-learning platforms if they are to be implemented permanently as distance learning platforms even after the end of the pandemic that is also applicable to any other countries.
\end{abstract}

Keywords: e-learning, distance learning, previous experience, self-efficacy, COVID-19 pandemic

\section{INTRODUCTION}

Distance education has become a strategic choice for the education system in all over the world that includes the Kingdom of Saudi Arabia, especially after the COVID-19 pandemic (Hebebci et al., 2020; Kim, 2020; Sun et al., 2020). This does not mean that educational institutions in the Kingdom of Saudi Arabia have not paid any attention to distance education programs previously as there have been several initiatives in this regard (Alahmari, 2017). For example, is Tatweer, the King Abdullah Project for the Development of Education, one 
of the biggest projects directed at developing education in Saudi Arabia. This project began in the year of $1428 \mathrm{AH}$ (2007), and it aimed to effectively contribute to raising the competitiveness of the Kingdom of Saudi Arabia and building a knowledge society through a set of programs such as: 1- Building an integrated system for educational standards, evaluation, and accounting 2-Improving the school environment to enhance education, and 3- Employing information and communication technology (ICT) to improve education (Ministry of Education 2017).

Just like in almost every other country in the world, COVID-19 pandemic has disrupted educational system in Saudi Arabia. It forced almost every school, as opposed to only specific schools, to move to online learning method in place of face-to-face meetings (Alammary et al., 2021). As a result, a comprehensive study that can help all public and private schools adopt and generalize the pattern of distance education is necessary. Also, understanding it from students' perspective is crucial considering they play a more central role in this distance education approach. As such, this paper will examine students' readiness and willingness to use distance education platforms using Davis' (1989) Technology Acceptance Model (TAM) as a theoretical framework. The results from this study can help answer a follow-up question of how this experiment can succeed if it is implemented continuously and permanently even after the pandemic is over. This study is the first of its kind so far to study students' acceptance of e-learning platforms as a means of distance learning during COVID-19 pandemic in Saudi Arabia and how the acceptance may vary across different groups of students along with factors associated with it.

The remainder of this paper is structured as follows. In the next section, we elaborate the rationale for adopting TAM as the theoretical framework before explaining our proposed model and the research method. Finally, we present the results of the hypothesis tests and discuss the implications of this study before wrapping it up with the conclusion.

\section{LITERATURE REVIEW}

We conducted a systematic literature review on the use of e-learning in Saudi Arabia in addition to some research on the e-learning acceptance models around the world using three major databases, i.e., Web of Science, Scopus, and Google Scholar. The results from this literature review are used in finding the research gap to be addressed by this study, helping develop the model and measures used in this study, and to cross validate its findings by putting it in context.

\section{The Saudi Arabian Initiatives in Distance Learning}

\section{Future Gate Project}

In light of this interest directed by the Saudi Ministry of Education in activating the methods of distance education, the Future Gate Project appeared in 1439 AH (2018). This project was aimed to provide an educational platform intended to serve students and teachers at public schools in Saudi Arabia. This project is considered a paradigm shift in Saudi schools at that time. The project was launched simultaneously in 150 schools in each of Riyadh, Jeddah, and the Eastern Region, and the goal was to reach 1500 schools and to be fully applied in all schools of the kingdom (Al-Ohali et al., 2019).

In this project, the Saudi Ministry of Education provided all the physical equipment as follows: (internal networks in schools, connection to the Internet, portable computers for teachers only, interactive digital display devices in all classrooms). This equipment was available in all schools implementing the Future Gate project at that time (Al-Ohali et al., 2018, Alshmrani \& Almalki, 2020). This is in addition to preparing and providing specialized training programs directed to all school members in the schools that implement the project.

\section{Madrasati (MySchool)}

Madrasati is an e-learning management system that includes a variety of digital educational tools that support education and distance learning processes and contribute to the educational objectives of Saudi 
Arabia's educational curricula. Additionally, it assists in the development of skills, values, and knowledge for all students in order to meet the digital requirements of the present and future in order to achieve the Kingdom of Saudi Arabia's 2030 goals and vision. The Madrasati platform has become an urgent necessity amid the COVID-19 pandemic, as all schools in the Kingdom of Saudi Arabia have been closed. And with the existence of such a platform, the continuation of education became possible and available to all students in the Kingdom of Saudi Arabia (Ministry of Education, 2020).

\section{Research Gap}

These two examples may reflect the Saudi government's interest in providing modern education styles, including distance education even before the COVID-19 pandemic. Unfortunately, these aforementioned projects have not received extensive study in order to know the extent of their benefit and what are the desired educational outcomes that have been obtained through these projects. The idea of using educational platforms remotely has appeared these days, and this idea is somewhat new in the Saudi context. So far, very few studies have discussed the e-learning platforms as a means of distance learning (i.e. FGP or Madrasati) and their focus was mostly on the concerns of teachers in specific schools in adopting these platforms and the challenges and the difficulties in using it (Al-Ohali et al., 2018; Masmali, 2020).

In Saudi Arabian context, Al-Ohali et al. (2018) discussed the FGP and aimed to identify the main parts of this portal while providing a report on the most important challenges that this project faced, and what methods were dealt with to overcome these challenges. Also, this study aimed to present a case study that could be used for countries planning to develop similar initiatives. Meanwhile, Masmali (2020) discussed the concerns of middle and high school teachers in adopting the Future Gate project, as this study aimed to examine teachers' fears through the framework of the Concern-Based Adoption Model (CBAM). That study showed that the teacher's concerns were focused on the following: 1- Technology and the Internet in the school; 2Ways to activate the portal; 3- How students deal with the portal. However, that study was limited to understanding the needs of teachers to implement innovations, and to understanding their concerns regarding the adoption of educational digital transformation programs in Saudi Arabia. It did not discuss the willingness and the readiness of both teachers and students alike to activate and use distance education platforms. It also did not measure their satisfaction with what is presented through these educational platforms. Also, these studies generally neglected the effect of self-efficacy on the performance of both teachers and students while using these platforms.

\section{THEORETICAL FRAMEWORK}

The Technology Acceptance Model (TAM) that was first introduced by Davis (1989) has been adopted by researchers to help explain and predict human's intention to adopt a new technology for a while, including in the context of distance education. The two main predictors of behavioral intention (BI) in TAM are perceived usefulness (PU) and perceived ease of use (PEU), both mediated by attitude. Over the time, TAM was also used by Venkatesh et al. (2003) to develop another model called the Unified Theory of Acceptance and Use of Technology (UTAUT) that added two new constructs to predict BI, namely social influence (SI) and facilitating conditions (FC) in addition to removing the mediator variable of attitude (ATT) than in many cases show too strong of a correlation with $\mathrm{BI}$ that they may have poor discriminant validity as a result. Furthermore, in the context of the education system, Park et al. (2012) showed that self-efficacy is another important factor behind students' acceptance of a new educational technology. Finally, we proposed another construct to measure students' previous experiences as another predictor of their acceptance toward the elearning platforms.

\section{Previous Experiences (PEX)}

We defined PEX in this study as the degree to which an individual has some previous technical experiences that can help them use the e-learning platforms. We argue that PEX is an important factor behind self-efficacy (SE). Students who have more previous experience will have a better self-efficacy that can help them use and 
navigate the e-learning platforms by themselves. Therefore, we hypothesized PEX to be the direct antecedent of self-efficacy (SE).

H1: PEX has a positive effect on SE.

\section{Social Influence (SI)}

In this study, we define SI as the individual's perception that others would think they should use the FGP. In secondary school students, $\mathrm{SI}$ is shown to help them see a new technology as easier to use (Pratama, 2020). In the absence of an official support system, students can use their inner circle to help them. Hence, we hypothesized SI to be the direct antecedent of perceived ease of use (PEU).

H2: SI has a positive effect on PEU.

\section{Perceived Ease of Use (PEU)}

As one of the two original constructs in TAM as specified in Davis (1989) and Davis et al. (1989), we defined PEU in this study as the individual's perception that using the e-learning platforms would be rather effortless. Students will not see e-learning platforms as useful and will less likely develop an intention of using it if they see FGP as difficult to use in the first place. Therefore, we hypothesized that PEU is a direct antecedent of both perceived usefulness (PU) and behavioral intention (BI).

H3: PEU has a positive effect on PU.

H4: PEU has a positive effect on BI.

\section{Perceived Usefulness (PU)}

As the other one of the two original constructs in TAM as specified in Davis (1989) and Davis et al. (1989), we defined PU in this study as the individual's perception that using the FGP would improve their performance. Students will have more incentive to use e-learning platforms if they see it as useful and effective in improving their educational attainment. Hence, as it is in the original TAM, we hypothesized that PU is a direct antecedent of $\mathrm{BI}$.

H5: PU has a positive effect on BI.

\section{Facilitating Conditions (FC)}

FC is introduced by Venkatesh et al. (2003) as a new construct that can predict BI in the UTAUT model. In this study, we defined FC as the individual's belief that an organizational and technical infrastructure exists to support the use of the e-learning platforms. As discussed earlier, in this context FC is represented by both the equipment and the training provided by the government. We hypothesized that $\mathrm{FC}$, albeit not as strong as other predictors, is still a direct antecedent of BI.

H6: PU has a positive effect on BI.

\section{Self-Efficacy (SE)}

In this study, we defined SE as an individual's judgment of their own ability to use the e-learning platforms. Park et al. (2012) showed that self-efficacy, which is considered as an internal motivational factor behind new technology adoption, is another important factor behind students' acceptance of a new educational technology. Hence, we hypothesized that SE is a direct antecedent of BI.

H7: SI has a positive effect on BI.

The proposed model with all hypothesized relationships between all constructs is shown in Figure 1. 


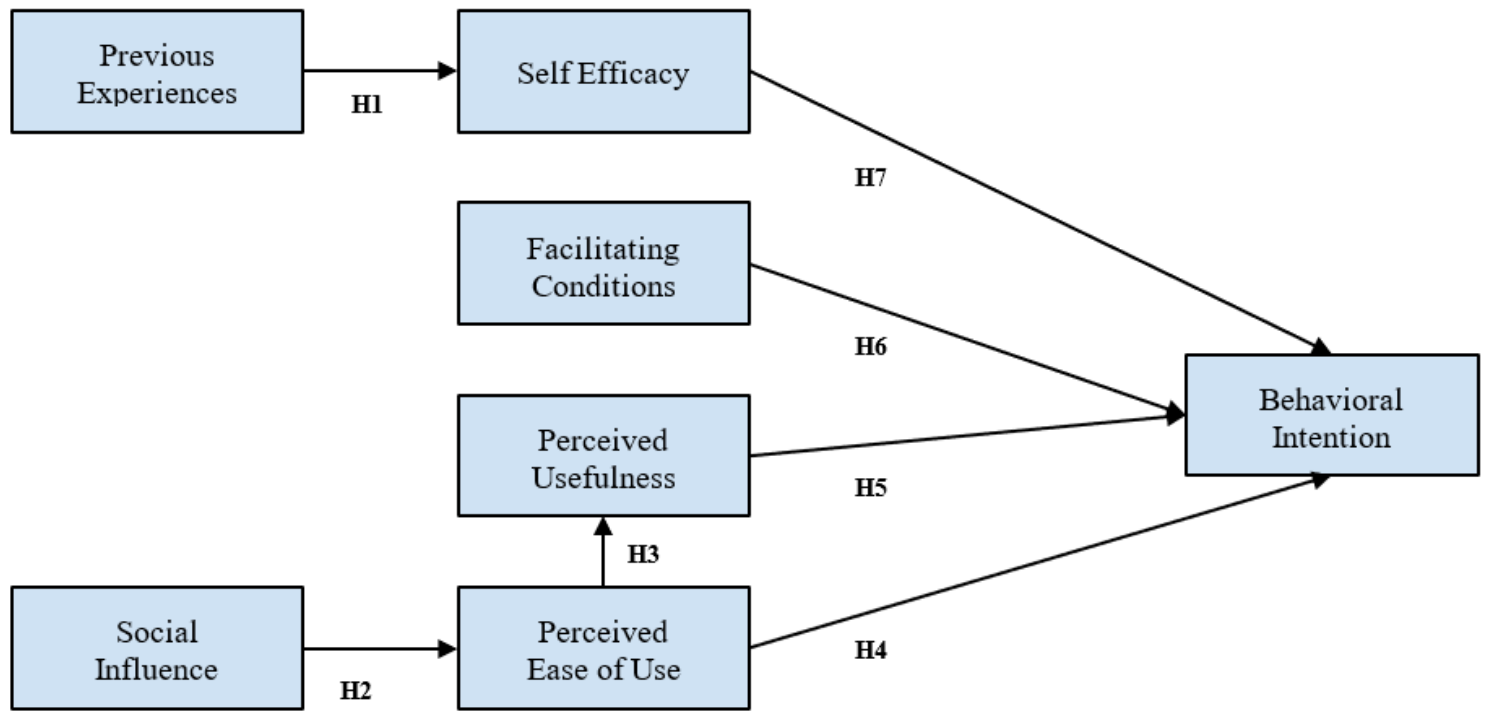

Figure 1. The proposed model in this study

\section{METHODOLOGY}

\section{Data Collection}

This study was conducted in public education schools in Makkah, Kingdom of Saudi Arabia, specifically in the Education Office in the Central of Makkah. As the Makkah Educational Zone is divided into eight education offices (North, South, East, West, Central, Bahra, Al-Jamum, Al-Kamil) each education office represents the general administration to supervise the public schools affiliated with each office. This study is part of a large research project to find out the effect of remote study on both students and teachers. In this study, the focus will be on students, where a group of secondary schools were selected at the Education Office in the Central of Makkah. As per the General Administration of Education in Makkah Region, there are 13 secondary schools, with a total of 5697 students for the academic year of 1440-1441 AH or 2018-2019 (Ministry of Education, 2019). Elementary schools have been excluded from the study since research concepts are not properly understood by elementary school students, since these concepts are related to knowing the effect of remote study and the extent to which students and teachers accept it. The necessary approvals and consents were taken to conduct the study, either from the Education Department, or from the students' parents and the adult students themselves, to distribute the questionnaire for the study to them. The questionnaire was distributed electronically, and students were asked to fill it out in a Likert-scale format. A link to the electronic questionnaire was sent to school principles to circulate it to the students. A total of 353 students filled out the questionnaire, but some incomplete or illogical answers to the questionnaires, amounting to 88 responses were omitted from the analysis. The final dataset consists of 265 participants, which is equal to $75 \%$ completion rate. Table 1 summarizes the characteristics of all student participants in this study.

Table 1. Student participants' description $(n=265)$

\begin{tabular}{lcc}
\hline Variables & Frequency & Percentages (\%) \\
\hline Sex & 197 & 74.34 \\
$\quad$ Male & 68 & 25.66 \\
$\quad$ Female & & \\
\hline Age group & 81 & 30.57 \\
$\quad$ Middle school & 184 & 69.43 \\
$\quad$ High school & & \\
Grade & 52 & 19.62 \\
$\quad$ First year & 102 & 38.49 \\
$\quad$ Second year & 111 & 41.89 \\
$\quad$ Third year & & \\
\hline
\end{tabular}




\section{Measures}

As indicated in Table 2, we adapted the majority of the items used to measure all constructs in this model from four previous studies. This was done to ensure the scales' content validity, ensuring that each item accurately represents the concept on which generalizations are to be made. In addition, we developed three items to measure the new construct of Previous Experience (PEX) that we introduced in this model.

Table 2. Measurement items

\begin{tabular}{|c|c|c|c|}
\hline No & Construct & Items & Adopted from \\
\hline 1 & $\begin{array}{l}\text { Social Influence } \\
\text { (SI) }\end{array}$ & $\begin{array}{l}\text { 1. People who influence my behavior will think that I should use e- } \\
\text { learning platforms. } \\
\text { 2. My classmates will think that I should use the e-learning platforms } \\
\text { 3. My family will think that I should use the e-learning platforms }\end{array}$ & $\begin{array}{l}\text { Wang et al. (2009) } \\
\text { Pratama (2020) }\end{array}$ \\
\hline 2 & $\begin{array}{l}\text { Perceived Ease of } \\
\text { Use (PEU) }\end{array}$ & $\begin{array}{l}\text { 1. Using the e-learning platforms would not require a lot of my } \\
\text { mental effort } \\
\text { 2. My interaction with the e-learning platforms would be clear and } \\
\text { understandable } \\
\text { 3. The e-learning platforms would be easy to use }\end{array}$ & $\begin{array}{l}\text { Huang et al. (2007) } \\
\text { Pratama (2020) }\end{array}$ \\
\hline 3 & $\begin{array}{l}\text { Perceived } \\
\text { Usefulness (PU) }\end{array}$ & $\begin{array}{l}\text { 1. The e-learning platforms would improve my teaching performance } \\
\text { 2. The e-learning platforms can improve the efficiency of teaching } \\
\text { 3. Overall, the e-learning platforms would be useful }\end{array}$ & $\begin{array}{l}\text { Huang et al. (2007) } \\
\text { Park et al. (2012) } \\
\text { Pratama (2020) }\end{array}$ \\
\hline 4 & $\begin{array}{l}\text { Facilitating } \\
\text { Conditions (FC) }\end{array}$ & $\begin{array}{l}\text { 1. I can easily get information or support for the e-learning platforms } \\
\text { 2. My school has been helpful in the use of the e-learning platforms } \\
\text { 3. My teacher has been helpful in the use of the e-learning platforms } \\
\text { 4. The government has been helpful in the use of the e-learning } \\
\text { platforms }\end{array}$ & $\begin{array}{l}\text { Park et al. (2012) } \\
\text { Pratama (2020) }\end{array}$ \\
\hline 5 & $\begin{array}{l}\text { Previous } \\
\text { Experience (PEX) }\end{array}$ & $\begin{array}{l}\text { 1. I have some experience with the technology (devices and software) } \\
\text { for the e-learning platforms } \\
\text { 2. I have some experience using a similar system to the e-learning } \\
\text { platforms } \\
\text { 3. I have some experience with the business process of the e-learning } \\
\text { platforms }\end{array}$ & $\begin{array}{l}\text { Developed by the } \\
\text { authors }\end{array}$ \\
\hline 6 & Self-Efficacy (SE) & $\begin{array}{l}\text { 1. I have the necessary skills for the e-learning platforms } \\
\text { 2. I am a skillful user in technology (devices and software) for the e- } \\
\text { learning platforms } \\
\text { 3. I have confidence in complementally using technology (devices and } \\
\text { software) for the e-learning platforms } \\
\text { 4. I understand technological terms well for the e-learning platforms }\end{array}$ & Park et al. (2012) \\
\hline 7 & $\begin{array}{l}\text { Behavioral } \\
\text { Intention (BI) }\end{array}$ & $\begin{array}{l}\text { 1. I have the intention to use the e-learning platforms } \\
\text { 2. I am going to positively utilize the e-learning platforms } \\
\text { 3. I will be a power user in the e-learning platforms }\end{array}$ & $\begin{array}{l}\text { Park et al. (2012) } \\
\text { Pratama (2020) }\end{array}$ \\
\hline
\end{tabular}

\section{RESULTS}

\section{Measurement Model}

We conducted a two-step approach using a measurement model and a structural model evaluation to establish the reliability and validity of the constructs before assessing the structural relationship of the proposed model, as recommended by Anderson \& Gerbing (1988). Then, we ran the Structural Equation Modeling (SEM) in R 3.6.3 with the lavaan 6.7 library (Rosseel, 2012).

After a few iterations of measurement and structural model evaluations, we omitted some items from the construct as their inclusions introduced some problems with either the convergent validity or the overall goodness of fit of the model. The final results of the assessment of the measurement models are presented in Table 3. Based on the factor loadings of all items as well as the Cronhach's alpha and composite reliability values of all constructs, the measurement models showed adequate reliability. The AVE values also indicated 
that the conditions for the convergent validity requirements were met. The discriminant validity of both models was evaluated by using the heterotrait-monotrait ratio of correlations (HTMT) approach. As suggested by Henseler et al. (2015), no correlations among all constructs to reach 0.90 threshold as shown in Table 4 means that the discriminant validity requirements were met.

Table 3. Convergent validity and internal reliability for student participants

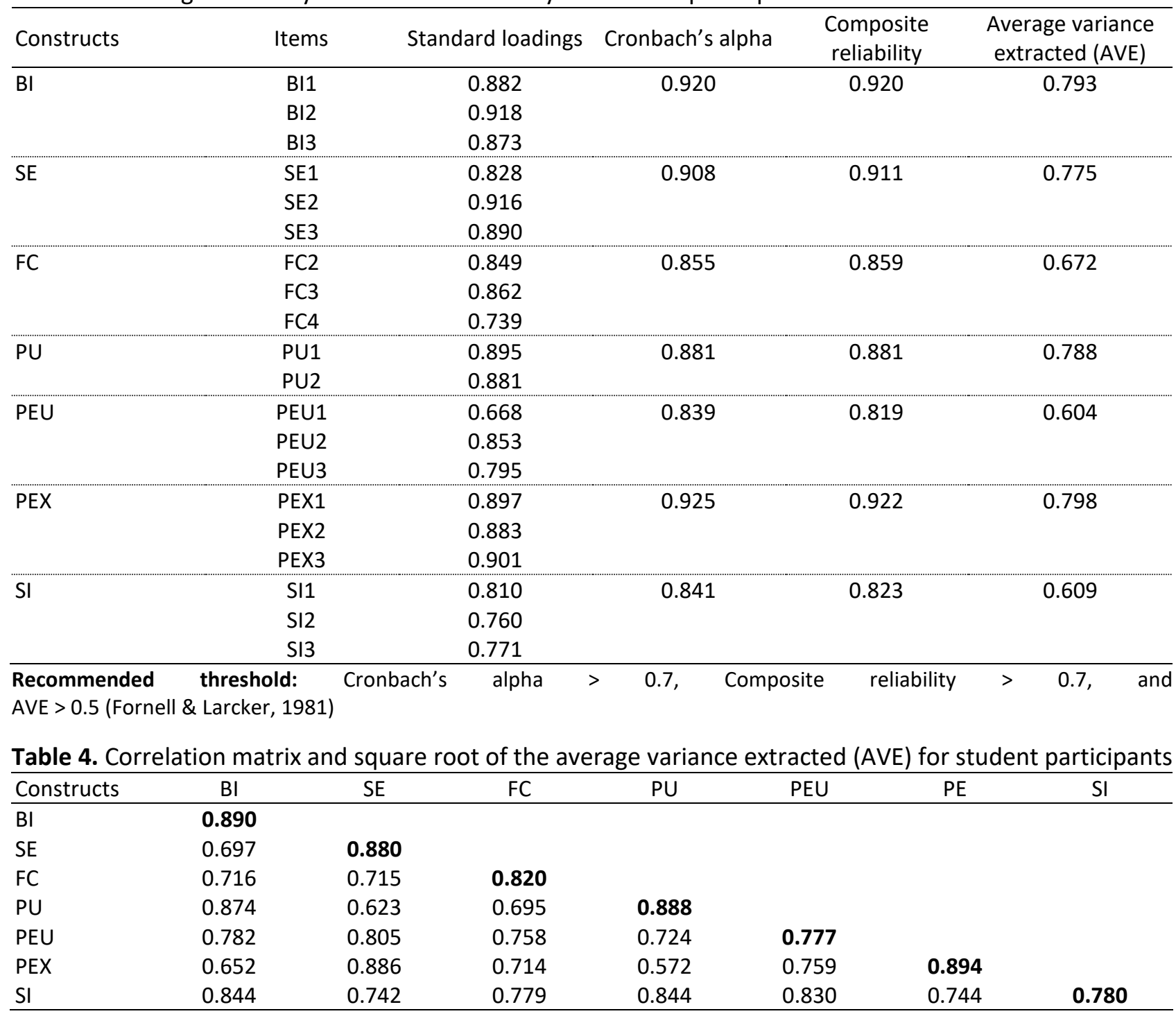

Recommended threshold: Correlation < 0.90 (Henseler et al., 2015)

We computed five common model-fit measures, i.e., the ratio of $\chi^{2}$ to degrees of freedom (df), standardized root mean square residual (SRMR), root mean square error of approximation (RMSEA), comparative fit index (CFI), and Tucker-Lewis Index (TLI) to evaluate the overall goodness of fit for both models. As shown in Table 5, all the model-fit indices exceeded their respective common acceptance levels suggested by previous research, including the two-index presentation strategy of SRMR and CFI/TLI proposed by $\mathrm{Hu}$ and Bentler (1999); thus, demonstrating that the measurement model fit the data reasonably well.

Table 5. Goodness-of-fit measures for student participants

\begin{tabular}{lccc}
\hline Measure & Model value & Recommended value & Source \\
\hline$\chi^{2} /$ df & 2.19 & $<3.00$ & Kline (2015) \\
SRMR & 0.05 & $\leq 0.08$ & Hu and Bentler (1999) \\
RMSEA & 0.07 & $\leq 0.08$ & MacCallum et al. (1996) \\
CFI & 0.96 & $\geq 0.95$ & Hu and Bentler (1999) \\
TLI & 0.95 & $\geq 0.95$ & Hu and Bentler (1999) \\
\hline
\end{tabular}


Standardized path coefficients in the hypothesized model are shown in Table 6 and Figure 2. Six out of seven hypotheses in the model were supported. Only facilitating conditions turned out to have no significant effect on behavioral intention of using the e-learning platforms. Altogether, the model accounted for $81.5 \%$ of the variance in behavioral intention for the students to use the e-learning platforms.

Table 6. Standardized estimates of all predictors of BI

\begin{tabular}{lccc}
\hline Relationship & Direct effect & Indirect effect & Total effect \\
\hline $\mathrm{PEX} \rightarrow \mathrm{BI}$ & - & $0.090 ; \mathrm{p}=0.069(\wedge)$ & $0.090 ; \mathrm{p}=0.069\left(^{\wedge}\right)$ \\
$\mathrm{SI} \rightarrow \mathrm{BI}$ & - & $0.670 ; \mathrm{p}<0.001\left(^{* * *}\right)$ & $0.619 ; \mathrm{p}<0.001\left(^{* * *}\right)$ \\
$\mathrm{PEU} \rightarrow \mathrm{BI}$ & $0.267 ; \mathrm{p}=0.016\left(^{*}\right)$ & $0.466 ; \mathrm{p}<0.001\left(^{* * *}\right)$ & $0.713 ; \mathrm{p}<0.001\left(^{* * *}\right)$ \\
$\mathrm{PU} \rightarrow \mathrm{BI}$ & $0.544 ; p<0.001\left(^{* * *}\right)$ & - & $0.544 ; \mathrm{p}<0.001\left(^{* * *}\right)$ \\
$\mathrm{FC} \rightarrow \mathrm{BI}$ & $0.079 ; \mathrm{p}=0.252$ & - & $0.079 ; \mathrm{p}=0.252$ \\
$\mathrm{SE} \rightarrow \mathrm{BI}$ & $0.100 ; \mathrm{p}=0.069(\wedge)$ & - & $0.100 ; \mathrm{p}=0.069\left(^{\wedge}\right)$ \\
\hline
\end{tabular}

${ }^{\wedge} \mathrm{p}<0.1 ;{ }^{*} \mathrm{p}<0.05 ;{ }^{* *} \mathrm{p}<0.01 ;{ }^{* * *} \mathrm{p}<0.001$

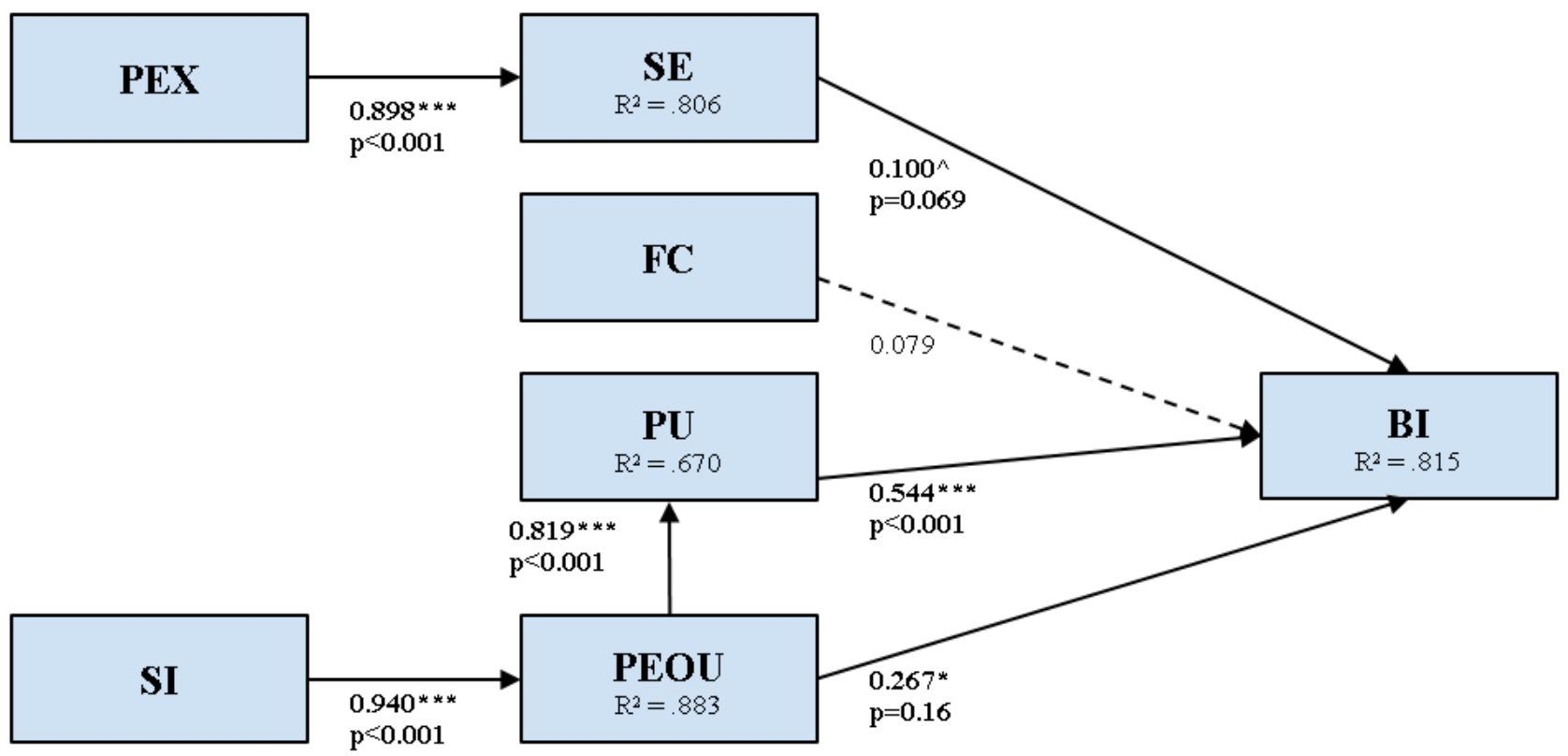

Figure 2. Path coefficients for student's acceptance of distance learning platforms

\section{Structural Model and Hypotheses Tests}

The results of path analysis show that 6 out of 7 direct paths in the proposed model are significant, indicating that $\mathrm{H1}, \mathrm{H} 2, \mathrm{H} 3, \mathrm{H} 4, \mathrm{H} 5$, and $\mathrm{H} 7$ are supported. Only $\mathrm{H} 6$ turned out to be not significant in this model. Figure 2 shows the coefficients of all the hypothesized paths in the model. Meanwhile, Table 6 summarizes the direct, indirect, and total effects of all factors on BI.

\section{Moderating Effects of Sex and Age Group}

We ran two multiple group SEM analyses to investigate whether sex and age group differences have a moderation effect on any factors in this model. We compared the total effects of each factor to BI between males and females for the sex differences and between middle school students and high school students for the age group differences. The results are summarized in Table $\mathbf{7}$ for sex differences and Table $\mathbf{8}$ for age group differences. 
Table 7. Moderating effects of sex

\begin{tabular}{lcccc}
\hline Relationship & Female Std.Beta & Male Std.Beta & Std.Beta difference & p-value \\
\hline $\mathrm{PEX} \rightarrow \mathrm{BI}$ & -0.009 & $0.121^{*}$ & 0.130 & 0.277 \\
$\mathrm{SI} \rightarrow \mathrm{BI}$ & $0.857^{* * *}$ & $0.589^{* * *}$ & $0.268^{*}$ & 0.031 \\
$\mathrm{PEU} \rightarrow \mathrm{BI}$ & $0.929 * * *$ & $0.630^{* * *}$ & $0.299^{*}$ & 0.031 \\
$\mathrm{PU} \rightarrow \mathrm{BI}$ & 0.351 & $0.552^{* * *}$ & 0.201 & 0.726 \\
$\mathrm{FC} \rightarrow \mathrm{BI}$ & -0.048 & $0.141^{\wedge}$ & 0.190 & 0.205 \\
$\mathrm{SE} \rightarrow \mathrm{BI}$ & -0.009 & $0.137^{*}$ & 0.147 & 0.224 \\
\hline
\end{tabular}

$\wedge p<0.1 ; * p<0.05 ; * * p<0.01 ; * * * p<0.001$

Table 8. Moderating effects of age group

\begin{tabular}{lcccc}
\hline Relationship & Female Std.Beta & Male Std.Beta & Std.Beta difference & p-value \\
\hline $\mathrm{PEX} \rightarrow \mathrm{BI}$ & $-0.196^{*}$ & $0.227^{* * *}$ & $0.422^{* * *}$ & $<0.001$ \\
$\mathrm{SI} \rightarrow \mathrm{BI}$ & $0.877^{* * *}$ & $0.536^{* * *}$ & $0.341^{\wedge}$ & 0.057 \\
$\mathrm{PEU} \rightarrow \mathrm{BI}$ & $0.889^{* * *}$ & $0.572^{* * *}$ & 0.316 & 0.115 \\
$\mathrm{PU} \rightarrow \mathrm{BI}$ & $0.501^{* * *}$ & $0.622^{* * *}$ & 0.121 & 0.391 \\
$\mathrm{FC} \rightarrow \mathrm{BI}$ & 0.079 & 0.095 & 0.016 & 0.956 \\
$\mathrm{SE} \rightarrow \mathrm{BI}$ & $-0.222^{*}$ & $0.252^{* * *}$ & $0.474^{* *}$ & 0.001 \\
\hline
\end{tabular}

$\wedge p<0.1 ;{ }^{*} p<0.05 ; * * p<0.01 ; * * * p<0.001$

Table 9 summarizes the results of hypothesis tests in this study where 6 out of 7 hypotheses $(H 1, H 2, H 3, H 4$, $\mathrm{H} 5$, and $\mathrm{H} 7$ ) are supported while the other one $(\mathrm{H} 6)$ is not. One hypothesis ( $\mathrm{H} 4)$ is moderated by sex differences, while another one $(\mathrm{H} 7)$ is moderated by age differences.

Table 9. Results of the hypotheses testing

\begin{tabular}{|c|c|c|c|c|c|c|}
\hline Hypothesis & Relationship & Std.Beta & Std.Error & z-value & $p$-value & Decision \\
\hline $\mathrm{H} 1$ & $\mathrm{PEX} \rightarrow \mathrm{SE}$ & 0.898 & 0.051 & 15.742 & $<0.001$ & Supported \\
\hline $\mathrm{H} 2$ & $\mathrm{SI} \rightarrow \mathrm{PEU}$ & 0.940 & 0.075 & 11.002 & $<0.001$ & Supported \\
\hline H3 & $\mathrm{PEU} \rightarrow \mathrm{PU}$ & 0.819 & 0.108 & 10.683 & $<0.001$ & Supported \\
\hline $\mathrm{H} 4$ & $\mathrm{PEU} \rightarrow \mathrm{BI}$ & 0.267 & 0.149 & 2.413 & 0.016 & Supported ${ }^{1}$ \\
\hline H5 & $\mathrm{PU} \rightarrow \mathrm{BI}$ & 0.544 & 0.080 & 6.448 & $<0.001$ & Supported \\
\hline H6 & $\mathrm{FC} \rightarrow \mathrm{BI}$ & 0.079 & 0.071 & 1.817 & 0.252 & Not Supported \\
\hline $\mathrm{H} 7$ & $\mathrm{SE} \rightarrow \mathrm{BI}$ & 0.100 & 0.065 & 1.817 & 0.069 & Supported ${ }^{2}$ \\
\hline
\end{tabular}

$\wedge \mathrm{p}<0.1 ;{ }^{*} \mathrm{p}<0.05 ;{ }^{* *} \mathrm{p}<0.01 ; * * \mathrm{p}<0.001$

${ }^{1}$ Significant for both sexes but is significantly stronger for females than males

${ }^{2}$ Significant for both age groups but the effect is in the opposite direction, negative for middle school students and positive for high school students

\section{DISCUSSION}

The findings from SEM analysis show that our model can explain $81.5 \%$ of the variance in students' acceptance of e-learning platforms used as a means of distance learning in the Kingdom of Saudi Arabia during COVID-19 pandemic. It indicates that our model has a high explanatory power and with all, but one factor shown as significant predictors of the acceptance of e-learning platforms. In this section we discuss the key findings and provide recommendations to policy makers to promote a better adoption of e-learning platforms among students.

First, our findings show that SE has a different effect on BI between the younger and the older students. SE positively affects $\mathrm{BI}$ for the older students in high school, but for some reason has a paradoxical negative effect on BI for the younger students in middle school. The model also shows that PEX is a significant predictor of SE among these students. In other words, both PEX and SE have paradoxical effects on $\mathrm{BI}$ among the younger students in middle school. The entire online experience for younger students was something new and very hard to comprehend. They were used to seeing their teachers and playing with their classmates in the traditional face to face learning setting. However, shutting down schools and adopting the full online learning methods have caused them to sit for hours in front of their tablets or laptop may have created negative experiences. Older students, on other hand, have more understanding of the situation and ability 
to manage their studies and interaction with their teachers and peers. Further, although schools have adopted technologies in the education systems because of COVID-19, they could not, due to the crisis circumstances, change their way of teaching to be more suitable for online teaching (Hodges et al., 2020). Classes start from $3 \mathrm{pm}$ and end at $7 \mathrm{pm}$ where students must sit for different classes with very short breaks causing students, especially younger ones, to get bored and distressed.

One plausible explanation on why both PEX and SE in younger students have negatively affected their $\mathrm{BI}$ is that the younger students grow up using electronic devices more for entertainment purposes (Arnott \& Yelland, 2020; Sulaymani et al., 2020). Another study found that $79 \%$ of younger students preferred to use entertainment applications while only 7.5\% used educational applications (Dialogue, 2017), so they have the perception that it is only used to play when these devices are used for online learning in the most traditional learning settings. Another plausible reason is that younger students are more accustomed to using mobile devices like smartphones or tablets as opposed to traditional computers like desktops or laptops. It is possible that the user experience (UX) of using the e-learning platforms on mobile devices is not as good as it is on desktops or laptops that offer a larger screen. If that is the case, it will be understandable that the more experienced younger students with mobile technology, the more they will dislike e-learning platforms that are not mobile friendly.

Second, we found that PEU is the most important factor in the model. The effect is even strongest for females and younger students in particular. Schools and policymakers need to focus on making e-learning platforms as easy as possible for students to adopt. An important way to ensure that the design of e-learning services is suitable and easy to use is to involve students in the designing and development process along with other stakeholders. Such involvement will result in better designing taking into consideration students' views and empowering them by giving them a voice (Hernández-Lara \& Serradell-López, 2018). We also found that SI is the main factor behind PEU, its total effect is the second strongest in the model after PEU, and its total effect is stronger for females than for males, which is in line with what the literature shows about the effect of SI on BI in Saudi Arabian university students that tended to be stronger among female than males (Bellaaj et al., 2015). In another study, female school administrators experienced greater levels of COVID-19 phobia than their male peers (Karakose et al., 2021), which may also have something to do with how SI has more effect among females in general. Furthermore, apart from structural support that is a top-down approach, SI can be cultural support that is more of a bottom-up approach. This finding indicates that students are more likely to seek support from their peers, parents, and teachers rather than the IT/ technical support for online learning services. In the Saudi schools' context, this may be due to several explanations. First, technical support may have delays or automated responses. The delay and the automated response can be explained due to the sudden transformation for online learning due as a response to COVID-19 pandemic, leading to almost six million Saudi students having access to the new e-learning platform (Ministry of Education, 2020). Thus, IT services and support were overwhelmed with a large number of requests as a result delay was expected. Therefore, students may find it very easy to ask their social circles. Another reason why SI was significant is that students may face the same problems when using e-learning platforms, so they discuss these problems and support each other or ask their teachers (Shyr \& Chen, 2018). Students utilize learning platforms to communicate with their teachers and with each other. Last but not least, the use of technology in general was very common among students therefore it was easy for them to use and support each other. One study found that more than $80 \%$ of Saudi households have access to the internet and electronic devices (Sulaymani et al., 2020).

Finally, the finding that FC is not significant indicates that simply providing the equipment is not enough. Training needs to be done effectively and technical support needs to be provided. As suggested in the literature, teachers should undergo professional development that focuses on the proper use of new technologies that they have not experienced before and should be provided with adequate technical support (Alammary et al., 2016). Although the ministry of education has responded quickly and invested in developing e-learning platforms as a response to enable schools to continue the learning process, a successful transformation requires that the ministry go further in supporting students and teachers to ensure successful implementation and adoption of these platforms among students and teachers. A good and well measured 
intervention that makes use of positive reinforcement and indirect suggestions can serve as a necessary nudge as shown in the literature (Pratama \& Firmansyah, 2020). Also, current teaching and learning methods during the pandemic rely more on home-school learning models whereas all the students' needs (devices and internet access) are provided by their parents. Therefore, parents' role might even be more important than the support given by schools and the government.

\section{CONCLUSIONS}

With a high explanatory power of $81.5 \%$, this model proposed in this study shows a theoretical significance in highlighting the different effects of self-efficacy and previous experience on the acceptance of e-learning platforms that are used as the underlying infrastructure of distance learning during COVID-19 pandemic by different age group of students. The paradoxical effects of self-efficacy and previous experience on the younger students may be attributed to the idea that they are more accustomed to different types of electronic devices (i.e., mobile devices) and thus sharing a different mindset compared to the older students. In terms of the practical implications, our findings suggest that the policymakers need to give more attention to the user experience (UX) side of the e-learning platforms. Providing e-learning platforms that are mobile friendly may be a good way to go. Not only because younger students are more accustomed to using mobile devices, but also because students who prefer mobile learning activities on their mobile devices tend to be active and collaborative learners themselves (Pratama \& Scarlatos, 2020). Also, as shown in the model, the e-learning platforms need to be as easy as possible for the students to use as students' perception on how easy the platforms to use is indeed the most important factor behind their acceptance.

Finally, because this research was carried out in the context of Saudi Arabia, it may not necessarily be applicable in a straightforward manner in other countries. For example, the severity of COVID-19 impacts, and the vaccination rates are not the same across the world and it may have a considerable impact toward education system in each country. Also, the differences in ICT infrastructures that has a strong bidirectional relationship with education (Pratama, 2017) may have introduced additional challenges for some countries (Maphosa, 2021). However, because COVID-19 is a global pandemic that has forced schools in almost every country to adopt the same distance learning approach in lieu of traditional face-to-face learning in classroom settings, there are more or less the same problems that may have a common source. In other words, the findings from this study are, to some extent, applicable to any other parts of the world facing the same COVID-19 pandemic. Indeed, it would be interesting to compare and contrast the findings of this study with those of similar studies conducted in different countries. Given that generational similarities across countries around the world seem to be stronger than cultural similarities across generations thanks to globalization, it would not be surprising to see similar findings in terms of students' acceptance of online learning platforms as a form of distance learning in different parts of the world amid this pandemic.

Author contributions: The first three authors contributed to the research design's conceptualization. The data were gathered by the first and third authors. The article's first draft was written by the corresponding author, who also analyzed and interpreted the data. Before reading and approving the final version of the article, all authors contributed to the writing of the literature review, discussion, and critical revision of the article. All authors approve final version of the article.

Funding: The authors received no financial support for the research and/or authorship of this article.

Declaration of interest: Authors declare no competing interest.

Data availability: Data generated or analysed during this study are available from the authors on request.

\section{REFERENCES}

Alahmari, A. (2017). The state of distance education in Saudi Arabia. Quarterly Review of Distance Education, 18(2), 91-98.

Alammary, A., Alshaikh, M., \& Alhogail, A. (2021). The impact of the COVID-19 pandemic on the adoption of e-learning among academics in Saudi Arabia. Behaviour \& Information Technology, 1-23. https://doi.org/10.1080/0144929X.2021.1973106 
Alammary, A., Carbone, A., \& Sheard, J. (2016). Blended learning in higher education: Delivery methods selection. In Proceedings of the Twenty-Fourth European Conference on Information Systems, Istanbul, Turkey.

Al-Ohali, Y., Alhojailan, M., Palavitsinis, N., Najjar, J., Koutoumanos, A., \& AlSuhaibani, A. (2019, July). Human factors in digital transformation of education: Lessons learned from the Future Gate at Saudi K-12. The International conference on applied human factors and ergonomics (pp. 52-64). Springer. https://doi.org/10.1007/978-3-030-20135-7_5

Al Ohali, Y., Al Suhaibani, A., Palavitsinis, N., \& Koutoumanos, A. (2018, November). Digital transformation of education in the Kingdom of Saudi Arabia: Deploying a country-wide learning management system for K-12 education. The 17th European conference on e-learning (pp. 1-2). Athens, Greece.

Alshmrani, Z. A., \& Almalki, A. (2020). The role of mathematics teachers in activating the future gate tools in public schools in Jeddah Governorate. Journal of Educational and Psychological Sciences, 4(46), 21-39. https://doi.org/10.26389/AJSRP.R130620

Anderson, J. C., \& Gerbing, D. W. (1988). Structural equation modeling in practice: A review and recommended two-step approach. Psychological Bulletin, 103(3), 411-423. https://doi.org/10.1037/0033-2909.103.3.411

Arnott, L., \& Yelland, N. J. (2020). Multimodal lifeworlds: Pedagogies for play inquiries and explorations. Journal of Early Childhood Education Research, 9(1), 124-146.

Bellaaj, M., Zekri, I., \& Albugami, M. (2015). The continued use of e-learning system: An empirical investigation using UTAUT model at the University of Tabuk. Journal of Theoretical \& Applied Information Technology, 72(3), 464-474.

Davis, F. D. (1989). Perceived usefulness, perceived ease of use, and user acceptance of information technology. MIS Quarterly, 13(3), 319-340. https://doi.org/10.2307/249008

Davis, F. D., Bagozzi, R. P., \& Warshaw, P. R. (1989). User acceptance of computer technology: A comparison of two theoretical models. Management Science, 35(8), 982-1003. https://doi.org/10.1287/mnsc.35.8.982

Dialogue, K. A. A. C. f. N. (2017). The survey of Saudi children's use of smart devices and electronic games. https://kacnd.org/News/NewsDetails/1391

Fornell, C., \& Larcker, D. F. (1981). Structural equation models with unobservable variables and measurement error: Algebra and statistics. Journal of Marketing Research, 18(3), 382-388. https://doi.org/10.2307/3151312

Hebebci, M. T., Bertiz, Y., \& Alan, S. (2020). Investigation of views of students and teachers on distance education practices during the Coronavirus (COVID-19) pandemic. International Journal of Technology in Education and Science, 4(4), 267-282. https://doi.org/10.46328/ijtes.v4i4.113

Henseler, J., Ringle, C. M., \& Sarstedt, M. (2015). A new criterion for assessing discriminant validity in variance-based structural equation modeling. Journal of the Academy of Marketing Science, 43(1), 115135. https://doi.org/10.1007/s11747-014-0403-8.

Hernández-Lara, A. B., \& Serradell-López, E. (2018). Student interactions in online discussion forums: Their perception on learning with business simulation games. Behaviour \& Information Technology, 37(4), 419-429. https://doi.org/10.1080/0144929X.2018.1441326

Hodges, C., Moore, S., Lockee, B., Trust, T., \& Bond, A. (2020). The difference between emergency remote teaching and online learning. Educause Review, 27. 
Hu, L.-T., \& Bentler, P. M. (1998). Fit indices in covariance structure modeling: Sensitivity to underparameterized model misspecification. Psychological Methods, 3(4), 424-453. https://doi.org/10.1037/1082-989X.3.4.424

Huang, J. H., Lin, Y. R., \& Chuang, S. T. (2007). Elucidating user behavior of mobile learning: A perspective of the extended technology acceptance model. The Electronic Library, 25(5), 585-598. https://doi.org/10.1108/02640470710829569

Karakose, T., Yirci, R., \& Papadakis, S. (2021). Exploring the interrelationship between COVID-19 phobia, workfamily conflict, family-work conflict, and life satisfaction among school administrators for advancing sustainable management. Sustainability, 13(15), 8654. https://doi.org/10.3390/su13158654

Kim, J. (2020). Learning and teaching online during COVID-19: Experiences of student teachers in an early childhood education practicum. International Journal of Early Childhood, 52(2), 145-158. https://doi.org/10.1007/s13158-020-00272-6

Kline, R. B. (2015). Principles and practice of structural equation modeling (4th ed.). The Guilford Press.

MacCallum, R. C., Browne, M. W., \& Sugawara, H. M. (1996). Power analysis and determination of sample size for covariance structure modeling. Psychological Methods, 1(2), 130-149. https://doi.org/10.1037/1082-989X.1.2.130

Maphosa, V. (2021). Teachers' perspectives on remote-based teaching and learning in the COVID-19 era: Rethinking technology availability and suitability in Zimbabwe. European Journal of Interactive Multimedia and Education, 2(1), e02105. https://doi.org/10.30935/ejimed/9684

Masmali, A. (2020). A mixed-methods study of examining the concerns of Saudi Arabian middle and secondary school teachers in adopting the future gate learning management system: A transformation to digital learning [Unpublished doctoral dissertation, Kansas State University].

Ministry of Education. (2017). Using tablets in the Saudis schools: Achieving 2030 vision. Saudi Arabia: Ministry of Education. www.moe.gov.sa

Ministry of Education. (2019). The statistical guide of the General Administration of Education in Makkah $\begin{array}{lllll}\text { Region for } & \text { the } & \text { (1440-1441 } & \end{array}$ https://drive.google.com/file/d/13dGxt484255K5gyJyo0K1e7clgz05LOQ/view

Ministry of Education. (2020). Madrasati is an e-learning management system: Ministry of Education. https://backtoschool.sa/

Park, S. Y., Nam, M. W., \& Cha, S. B. (2012). University students' behavioral intention to use mobile learning: Evaluating the technology acceptance model. British Journal of Educational Technology, 43(4), 592605. https://doi.org/10.1111/j.1467-8535.2011.01229.x

Pratama, A. R. (2017, March). Cross-country analysis of ICT and education indicators: An exploratory study. IOP Conference Series: Materials Science and Engineering, 185(1), 012006. https://doi.org/10.1088/1757-899X/185/1/012006

Pratama, A. R. (2020). Fun first, useful later: Mobile learning acceptance among secondary school students in Indonesia. Education and Information Technologies, 26(2), 1737-1753. https://doi.org/10.1007/s10639-020-10334-w

Pratama, A. R., \& Firmansyah, F. M. (2020). How can governments nudge students to become ebook readers? Evidence from Indonesia. Digital Library Perspectives, 37(3), 257-288. https://doi.org/10.1108/DLP-072020-0066 
Pratama, A. R., \& Scarlatos, L. L. (2020). The roles of device ownership and infrastructure in promoting elearning and m-learning in Indonesia. International Journal of Mobile and Blended Learning, 12(4), 116. https://doi.org/10.4018/IJMBL.2020100101

Rosseel, Y. (2012). lavaan: An R package for structural equation modeling. Journal of Statistical Software, 48(2), 1-36. https://doi.org/10.18637/jss.v048.i02

Shyr, W.-J., \& Chen, C.-H. (2018). Designing a technology-enhanced flipped learning system to facilitate students' self-regulation and performance. Journal of Computer Assisted Learning, 34(1), 53-62. https://doi.org/10.1111/jcal.12213

Sulaymani, O., Fleer, M., \& Chapman, D. (2020). A cultural-historical study of digital devices supporting peer collaboration in early years learning setting in one Saudi school. In A. Ridgway, G. Quiñones, \& L. Li (Eds.), Peer play and relationships in early childhood (pp. 113-127). Springer. https://doi.org/10.1007/978-3-030-42331-5_8

Sun, L., Tang, Y., \& Zuo, W. (2020). Coronavirus pushes education online. Nature Materials 19(6), 687-687. https://doi.org/10.1038/s41563-020-0678-8

Venkatesh, V., Morris, M. G., Davis, G. B., \& Davis, F. D. (2003). User acceptance of information technology: Toward a unified view. MIS Quarterly, 27(3), 425-478. https://doi.org/10.2307/30036540

Wang, Y. S., Wu, M. C., \& Wang, H. Y. (2009). Investigating the determinants and age and gender differences in the acceptance of mobile learning. British Journal of Educational Technology, 40(1), 92-118. https://doi.org/10.1111/j.1467-8535.2007.00809.x

Correspondence: Ahmad R. Pratama, Department of Informatics, Universitas Islam Indonesia, Yogyakarta, Indonesia. E-Mail: ahmad.rafie@uii.ac.id 